\title{
UTJECAJ PRIRODNO-GEOGRAFSKE OSNOVE NA RAZVOJ HRVATSKO-SLOVENSKE GRANICE
}

\author{
Andrija Bognar*
}

\section{Izvleček}

Stoletja stara slovensko-hrvaška meja je $v$ glavnem naravna, poteka po rekah in gorskih slemenih. To opredeljuje tudi organizacijo življenja $v$ obmejnih območjih. Nova meja to tudi potriuje, je odraz trenutnih odnosov, moči in interesov, kar ustvarja spore med dvema državama. To velja še posebej za mejo na rekah (Dragonja in Mura) in na morju.

Ključne besede: meja, naravno okolje, reke, slemena, morje

\section{INFLUENCE OF THE NATURAL-GEOGRAPHIC BASIS ON DEVELOPMENT OF THE CROATIAN-SLOVENE BOUNDARY LINE}

\begin{abstract}
The centuries-old parts of the Croatian-Slovene boundary line are mainly natural: fixed along the rivers and mountain ridges. The life organization of that area is accommodated to the boundary with subsequent characteristics. In principle, the more recent boundary line has been imposed, and it is the reflection of the momentary relations between the forces and interests, and so the source of the interstate disputes. This goes even for the boundary fixed along the rivers (Dragonja, Mura), and for the sea boundary.
\end{abstract}

Key words: boundary, natural, rivers, ridges, sea

*Dr., red. prof., Odsjek za geografiju, PMF, Univerza v Zagrebu, Maruličev trg 19, Zagreb, Hrvatska 
Političko - geografsko - teritorijalna podjela svijeta moguća je jedino uz postojanje što jasnijih i točnijih graničnih linija. Prema općoj definiciji odjeljuju se područja različitih geografskih, gospodarskih, političkih, etničkih, religijskih i drugih obilježja. Dovodeći to pitanje na odnose među državama, granice treba definirati kao linije koje dijele dva suvereniteta. Granične linije pri tome trebaju biti jasno definirane i demarkirane.

\section{Neke uvodne napomene}

U slučaju granice između R Hrvatske i R Slovenije treba naglasiti da se veći dio nje može, prema Poundsovim kriterijima (1963.), uvrstiti u tip subsekventnih granica. Sukladna je s prirodnim i kulturnim (fizionomskim i nodalno-funkcionalnim) granicama regija. Takove granice nastale su u pravilu nakon oblikovanja kulturnog krajolika. Naime, tijekom povijesti postajala je tendicija da se granice prilagode odvajanju kulturnih cjelina čije je nastojanje uz gospodarske i političke interese vezano i za etničke različitosti. Misli se tu prvenstveno na dijelove granice na rijeci Kupi, Bregani, Sutli i Muri te na gorskim uzvišenjima Žumberačke gore i Maceljske gore, uz koje se prilagođavala i prostorna organizacija života. Granična linija na navedenim sektorima ima dugi kontinuitet, čak od 10. ili 12. stoljeća na ovamo (Vidi kartu u radu M. Bufona, 1993/94. str. 178).

Dijelovi granice povučene u 20. st. (na rijeci Muri, dijelu Gorskog Kotara i Istri), poslije I. i II. svjetskog rata (1919., 1947. i 1954. godine), mada se također, uglavnom vežu za neke markantne prirodne prepreke (rijeka Dragonja i Mura), u cjelosti se mogu karakterizirati prema Poundsovoj klasifikaciji, kao nametnute ili superimposed granice. Ta činjenica svog izraza ima i u suvremenim graničnim sporovima dvaju suvereniteta nakon šło su 1991. godine, raspadom Jugoslavije, postale nezavisne države.

\section{Utjecaj prirodnogeografske osnove na obilježja recentne granice i na njen historijski razvoj}

Dužina kopnenin državnih granica R Hrvatske je 2028 km. R Slovenijom Hrvatska ima 501,3 km dugu granicu ili 24,7 \% njenih granica'. Prirodna osnova je u znatnoj mieri korištena $u$ delimitaciji i demarkiranju granice.

\footnotetext{
1 dužina granice R Hrvatske s R Mađarskom je 329 km ili 16,2\%, R Srbijom 241 km ili 11,9\%, R BIH $932 \mathrm{~km}$ ili 46,0 \% i R Crnom Gorom $25 \mathrm{~km}$ ili 1,2\% njenih granica (s Jugoslavijom ukupno $266 \mathrm{~km}$ ili $13,1 \%$ njenih granica).
} 
Ukoliko se u obzir uzmu granice na rijekama i potocima te grebenima gorskih uzvišenja čak $68,2 \%$ granične linije je vezano za markantne elemente prirodne osnove; granica na vodotocima duga je $288,0 \mathrm{~km}(57,4 \%)$ a na grebenima uzvišenja 54,1 km (10,8 \%). Dakle, samo na dužini od 159,2km (31,89\%) nije prilagođena nekoi prepoznatliivoi prirodnoi prepreci.

Tablica 1: Prirodno geografska utemeljenost kopnene državne granice R Hrvatske i $R$ Slovenije - granice na vodotocima i grebenima uzvišenja ${ }^{2}$

\begin{tabular}{|c|c|c|c|c|}
\hline & $\begin{array}{c}\text { Granica na rijekama } \\
\text { i potocima }(\mathrm{km})\end{array}$ & $\begin{array}{c}\text { Granica na } \\
\text { grebenima } \\
\text { Uzvišenia }(\mathrm{km})\end{array}$ & $\begin{array}{c}\text { Indiferentna } \\
\text { granica }(\mathrm{km})\end{array}$ & Ukupno \\
\hline $\begin{array}{c}\text { apsolutne } \\
\text { vrijednosti }\end{array}$ & 288,0 & 54,1 & 159,2 & 501,3 \\
\hline$\%$ & 57,5 & 10,8 & 31,8 & 100,0 \\
\hline
\end{tabular}

Podloga: topografske karte 1:100000 odgovarajučih sekcija, VGI Beograd

Još je izraženiij utjecaj prirodne osnove ako se uzmu u obzir sektori granice vezane za vršne padine gorskih uzvišenja Gorskog Kotara i Žumberačke gore koji su uz to zatvoreni šumski prostori s jasno izraženim izolacijskim funkcijama (nedostatak prometnica i veoma rijetka naselienost)). Uzmu li se i ti sektori u obzir tada granica na gorskim uzvišeniima ima 108,9 km ili 21,7\% ukupne državne granice, što ujedno povećava udio tzv. prirodnih granica na 396,9 km ili 79,2\%.

Tablica 2: Prirodno geografska utemeljenost kopnene državne granice R Hrvatske i R Slovenije - granice na vodotocima i na grebenima uzvišenja te vršnim padinama gorskih uzvišenja ${ }^{3}$

\begin{tabular}{|c|c|c|c|c|}
\hline & $\begin{array}{c}\text { Granica na } \\
\text { rijekama i } \\
\text { potocima }(\mathrm{km})\end{array}$ & $\begin{array}{c}\text { Granica na grebenima } \\
\text { uzvišenjima i vršnim } \\
\text { padinama uzvišenia } \\
(\mathrm{km})\end{array}$ & $\begin{array}{c}\text { Indiferentna } \\
\text { granica } \\
(\mathrm{km})\end{array}$ & Ukupno \\
\hline $\begin{array}{c}\text { apsolutne } \\
\text { vrijednosti }\end{array}$ & 288,0 & 108,9 & 104,4 & 501,3 \\
\hline$\%$ & 57,5 & 21,7 & 20,8 & 100,0 \\
\hline
\end{tabular}

Podloga: topografske karte 1:100000 odgovarajučih sekcija, VGI Beograd

\footnotetext{
2 analizu i izračun dužine pojedinih kategorija granice između R Hrvatske i R Slovenije izvršila je postdoktorantica dr. sc. Sanja Lozić kojoi se ovom prilikom zahvaljujem na uloženom trudu i predanosti

3 analizu i izračun dužine pojedinih kategorija granice između R Hrvatske i R Slovenije izvršila je postdoktorantica dr. sc. Sanja Lozić kojoi se ovom prilikom zahvaljujem na uloženom trudu i predanosti
} 


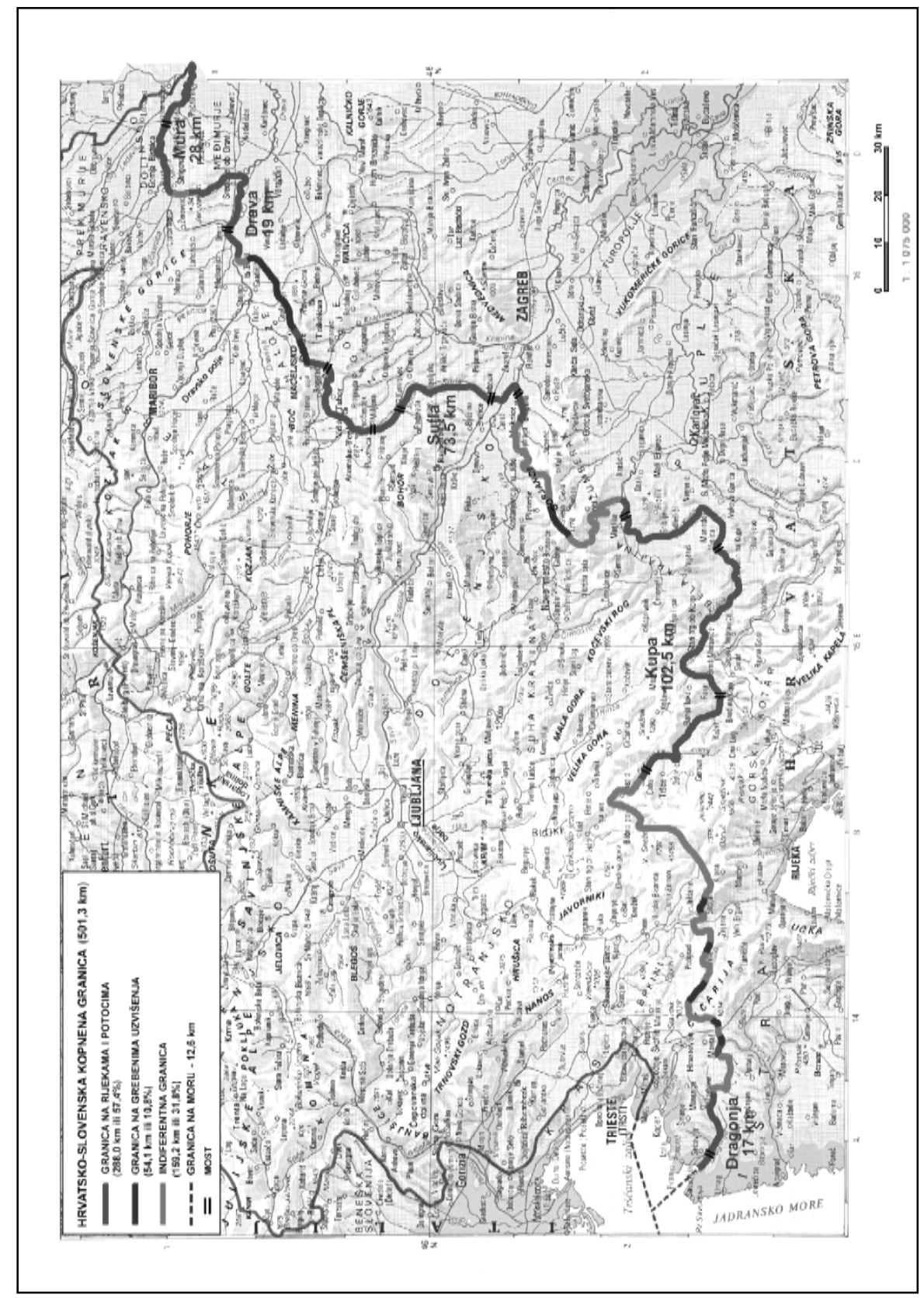


Nema sumnje da pri povlačenju granica do prvenstvenog izražaja dolaze politički, geostrateški i gospodarski interesi pojedinih suvereniteta. Vrijedi ta konstatacija čak i na drugostepenoj razini pri razgraničenju temeljnih administrativno teritorijalnih jedinica unutar pojedinih država (županija, oblasti i dr.) Svaka granica treba pri tome zadovoljiti tri temelina načela. S aspekta organizacije života prostora države trebaju biti prepoznatliive s obrambenostrateškog (lako branjiva i kontrolirana) i gospodarskog (pogranični prostor je od najmanjeg ekonomskog interesa, najpovoljniji prometni koridori) stanovištva te da su što kraće i malobrojnije. Prema tome najbolje granice će biti one koje zadovoljavaju sve navedene kriterije. Sa obrambeno - strateškog ali dijelom i gospodarstevnog stanovišta prirodne granice su najpogodnije. Prihvatljiva je ta konstatacija i s aspekta prepoznatljivosti. lako vobičajena podjela granica na prirodne i umjetne ne odražava najbolje složenost postoječe političke i geografske stvarnosti, sve su granice u svijetu de facto, umjetne i političke tvorevine utemeljene na odnosu snaga, pri čemu neke od njih mogu kao pogodnu oznaku na terenu koristiti neke prirodno - geografske sadržaje - vodotoci, reljef i vegetacijski pokrov (Pavić, 1973) ${ }^{4}$. Historijsko geografski razvoj Hrvatsko - Slovenskog pograničja ukazuje da su se u razgraničavanju pojedinih regija i političko - teritorijalnih entiteta (npr. Austrijskog carstva od Kraljevine Mađarske i Kraljevine Hrvatske - Slavonije) u znatnoj mieri koristile prirodne međe. Odnosi se to i na veći dio današnje granične linije koja odvaja R. Hrvatsku i R. Sloveniju. Upravo na tim svojim sektorima ona ima kontinuitet opstojnosti čak od 10-og odnosno 12-og stoljeća (Bufon, 1994.).

Vodotoci utjeću dvojako na organizaciju života prostora; s jedne strane privlače a s druge odbijaju. Političko - geografska uloga vodotoka je s toga vrlo kompleksna. Za Panonski bazen, izuzev viši planinski okvir te sredogorja "otočnog" karaktera, je karakteristično da im je uloga odvajanja daleko izraženija od njihove moći spajanja. Riječna granica je prihvatliiva samo u jednom slučaju, i to ako je ona stvarno u graničnom području koji zadovoljava prije navedena načela. Plovne rijeke međutim, to nisu u nikojem slučaju. Ako je to slučajno tako, takove granice su povijesno naslijeđe. Primjer toga je granica R Hrvatske i R Mađarska na Dravi između Terezinog Polja i ValpovoBelišće. Očito je dakle, nastala tijekom povijesnog razdoblja (X. i XI. stoljeća) kada korištenje rijeka kao plovnih putova nije imalo veću gospodarsku ulogu.

\footnotetext{
4 "Negativni geopolitički i geostrateški aspekti, takozvanih prirodnih granica leže prvenstveno u tome što se u ekspanzionističkim težnjama pojedinih velikih sila nikada ne zna do kojih su prirodnih granica usmjerene njihove "opravdane " teritorijalne aspiracije; sa jačanjem moći neke države, napuštaju se, naime, postojeće prirodne granice i traže nove, dakako, u širem teritorijalnom obuhvatu" (Pavić, 1973, str. 298)
} 


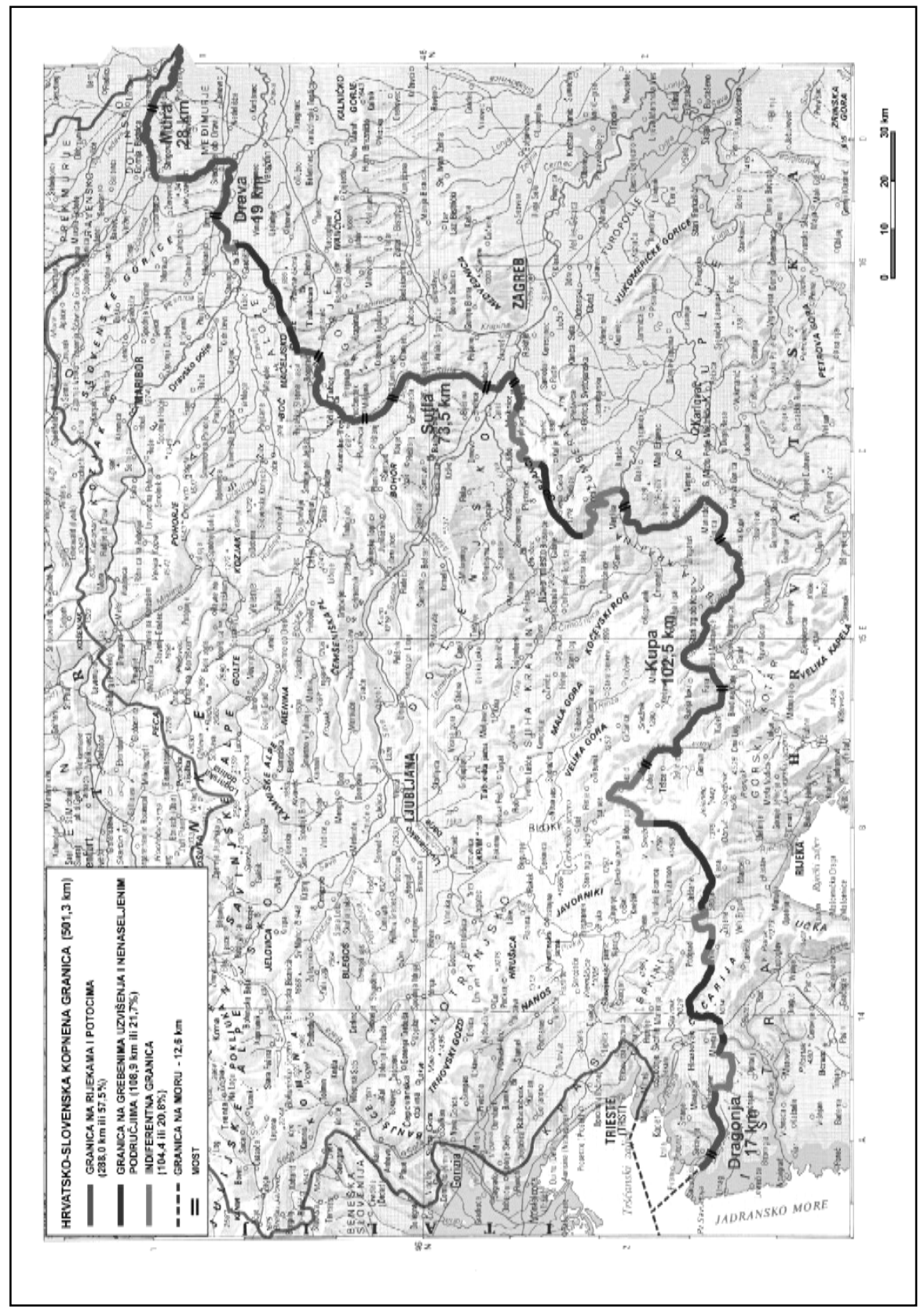


Takve granice danas imaju, ili su do nedavno imale, isključivo vojno značenje. Predstavljaju crtu odvajanja dvaju suprotstavljenih suvereniteta, na neki način simbol "najave rata". Takvih opasnosti u vezi riječnih granica između R Slovenije i R Hrvatske nema pošto Dragonja, Čabranka, Kupa, Bregana, Sutla i Mura nemaju, a niti su u prošlosti imale funkciju vodenih prometnih putova. Vrijedi za njih da nemaju niti veći HE potencijal, za razliku od rijeke Drave kao granice imeđu R Mađarske i R Hrvatske nizvodno od Botova ili rijeke Dunava u Malom Alfeldu gdje on odvaja $R$ Mađarsku i R Hrvatsku. Kako svaki od suvereniteta koji participiraju na takovim tokovima, ukoliko nema razumnog dogovora, želi prisvojiti vodotok u cjelosti a što na svoj način također predstavlia "casus belli". Izgradnja HE Gapčikovo od strane Slovaka i Nagymaros - a od Mađara i međudržavni spor oko toga svakako je dobar primjer, bez obzira na geoekološku opravdanost iskorištavanja HE ili pak na HE potencijale voda rijeku Dunav. Kako rijeka Sava, Drava i Mura (samo dijelom) nisu granične rijeke Slovenije s Hrvatskom, već samo protiču nizvodno teritorijem pribrežnih država mogućnost izbijanja sukoba oko njihovog HE korištenja svedena je na minimum. Eventualni sukobi mogu proisteći samo s aspekta neodgovarajućeg geoekološkog vrednovanja i valorizacije voda vodotoka, posebno glede zaštite okoliša.

Malo je regija u kojima su životne fasade vezane za pojedine rijeke. Primier toga su, uz odgovarajuće rezerve geostrateške prirode, županija Pest, Komarom, Esztergom, Bihar, Arad i Temes u srednjovjekovnoj Mađarskoj, Zagreb u srednjovjekovnoj Kraljevini Hrvatskoj te županije Pest i Csongrad te Zagrebačka i Osječko - Baranjska županija u suvremenoj R. Mađarskoj odnosno R. Hrvatskoj.

Daleko je više primjera da do izražaja dolazi, unatoč fizionomske sličnosti rijeci participirajučih krajeva - regija, prilagodba prostornih cjelina reljefnim odnosima. Obiliežje je to prvenstveno onih područja u kojima su vodotoci zbog specifičnih strukturno - geomorfoloških prilika (recentne potoline u nizinama) oblikovali široke naplavne, močvarne i ujezerene ravni s gustom mrežom starih korita i rukavaca (Kopački rit na sutoku Dunava i Drave, Kalocska potolina uz Dunav, široka naplavna ravan Drave kod Donjeg Miholica, Barcsa, Varaždina i Ormoža, Samoborska zavala, Lonjsko polje, Jelas polje i Bosutska nizina uz Savu) nastalih u uvjetima mehanizma voda donjeg toka, ili pak brojni migrirajući meandri, (nizina Drave, Mure, Save i Dunava) utjecajem mehanizma srednjeg toka. Prometno - gospodarstvena povezanost pribrežnih područja redovito se je, šło vrijedi najčešće i za najnovije doba, vezala za suženja sukcesija naplavnih ravni - potolina i kotlina (Mariborsko, Ormoško, Varaždinsko, Botovsko, Barcsko i Osječko na 
rijeci Dravi; zatim Donjolendavsko, Mursko Središčansko, Letenjsko, Kotoribansko na rijeci Muri; Brežičko, Zagrebačko, Novsko, Gradiščansko, Brodsko, Županjsko na rijeci Savi; Bratislavsko, Komarovsko, Esztergomsko, Peštansko, Bajsko, Batinsko, Erdutsko, lločko, Novosadsko, Beogradsko na rijeci Dunavu...) $i$ to tamo gdje su se nasuprotne ocjedite riječne terase ili terasne nizine najviše približile jedna drugoj. Karakteristika je to i granice $R$ Slovenije i R Hrvatske u dolini Sutle (Dobovsko - Harmički, Bizelisko Klanječki, Kumrovečki, Miljanski i Rogatečki mostni prijelazi) i dolini Kupe te Čabranke (Metlički, Gribljanski, Mrzljački, Vinički, Brodski i Osilnički mostni prijelazi). Na rijeci Dragonji u Istri zbog velike širine naplavne ravni i nestabilnosti korita postoji samo jedan relevantni mostni prijelaz (Sečovje) i jedan manji, sporedni (Dragonja). U načelu što je vodotok širi, njegovo korito nestabilnije (donji tok rijeke Dragonje u Istri, Mura, Drava, Sava i Dunav u panonskom prostoru), širina naplavne ravni veća a ledohod je izražen, prijelaz preko tih rijeka je teži, a izgradnja mostova zahtjevnija i skuplja, što rezultira njihovim manjim gospodarstvenim značenje u životu okolnih područja, pa će one tim prije dobiti ulogu granice. Dakako, to vrijedi i za vodotoke s sutjeskama (klisurama) i doline kanjonskih obilježja (Kupa, Bregana), obzirom da na njima i nema cestovnih i željezničkih komunikacija a mostni prijelazi su vrlo rijetki. Izolacijska funkcija takovih vodotoka naglašena je i činjenicom da su pribrežni prostori najčešće karakterizirani gustim šumskim pokrovom (Kupa i Čabranka).

Sasvim je druge prirode politička uloga onih vrsta riječnih granica koje su de facto izraz tzv. "školskog" utjecaja geografske karte pri njihovom povlačenju. Opće je naime, poznato da se prilikom političkih odluka za tzv. okruglim stolovima, posebno na mirovnim konferencijama, uzdužni profili pojedinih vodotoka (misli se na korita!), pa čak ako se radi o bezznačajnim, povremenim vodotocima, dolaze do posebnog izražaja pri povlačenju granica. Jednostavno upravo stoga, što na temelju nịhovog postojanja, odluka o povlačenju granice se može provesti najčešće "neodgovorno (delimitacija i demarkacija)" i to bez ikakovih prethodnih znanstveno utemeljenih studija. Samo to može protumačiti granicu $R$ Hrvatske i R Slovenije na rijeci Sutli nizvodno od Kumrovca i R Hrvatske i BiH na rijeci Uni. Istina, može se pretpostaviti da je pri povlačenju granice na Sutli u 10. stoljeću dolina rijeke bila nenaseljena i predstavljala zatvoreni šumski prostor, što znaći terru nullius. Kako nema odgovarajuće historijsko demografske dokumentacije, teško je ustanoviti koji su zapravo, naravno uz 
odnose snaga, čimbenici utjecali na povlačenje granica na Sutli i time uvjetovali podjeljenost prostorne cjeline porječja ${ }^{5}$.

$S$ prirodno - geografskog stanovišta posebno zanimliivo pitanje je povlačenje granice na rijeci Dragonji, osobito tamo gdje su nakon povlačenja talijanskog etnikuma neke hidromorfološke specifičnosti korištene kao temelj za različito interpretiranje stvarne linije razgraničenja. Misli se tu prvenstveno na razgraničenje dvaju suvereniteta $u$ donjem toku rijeke Dragonje. Poznavajući morfogenetske učinke vodotoka s osobinama mehanizma donjeg toka, a to je upravo tu rijeka Dragonja, jasno je da zbog česte promjene pravca otjecanja vodotoka i oblikavanja čitave mreže starih korita u antropogenom razdoblju točno određivanje državne granice je vrlo diskutabilno. Tim prije što se ono mijenjalo unutar vremenskog razdoblja od jednog stoljeća. Vjerovatno je da su tome razlog diferencirana recentna tektonska aktivnosti (subsidencijski pokreti) i njihov utjecaj na smier otjecenja vodotoka. Razumljivo je da takove promjene ne mogu pratiti odgovarajući politički i upravni postupci (podešavanje administrativno - teritorijalne i katastarske - imovinsko - pravne podjele) što je prilikom povlačenja državnih granica temeli za sporove dalekosežnih posljedica. Problem je time naglašeniji što se nije mijenjala niti granica dvaju etnikuma.

Problematika morskih granica je posebno zanimliiva jer je s obrambenog stajališta daleko pogodnija. Sadrži naime, daleko više pogodniijih obrambenih komponenti u odnosu na one kopnene. Na žalost, međutim, po pitanju državnih granica na moru nema opće prihvačenih kriterija. Obala se ni u

\footnotetext{
${ }^{5}$ U Panonskom prostoru u srednjem vjeku granice županija su često uključivale cjelokupni prostor nizina pojedinih tokova (terasnu nizinu i naplavnu ravan), koji su na prvi pogled činili okosnicu tih administrativno - teritorijalnih cjelina. Takav razvoj može se objasniti strateškim razlozima ili pak prilagođivanjem opskrbnoi sredini pojedinih plemena i rodova. Primjerice, Mađari su prilikom naseliavanja u 10. i 11. stoljeću osiguravali najvažnije prijelaze preko većih vodotoka (Baranja s cisdravskim dijelom županije, županija Komarom sjeverno i južno od Dunava, županija Pest zapadno i istočno od Dunava, Zalatska županija sjeverno i južno od Mure, Zagrebačka županija sjeverno i južno od Save) ili su pak osnivali županije koje su obuhvaćale cjelokupnu fluvijalnu nizinu koje su predstavljale jedinstvenu opskrbnu sredinu (primjerice županije Feher, Arad, Temes, Bihar...). Noviii razvoj administrativno - teritorijalne podjele Kraljevine Hrvatske i Slavonije i Kraljevine Mađarske, ali i Austriijke Carevine definiran je prvenstveno revolucionarnim društveno - gospodarstvenim razvojem panonskog bazena tijekom 18. i 19. i početkom 20. stoljeća (veliki uspjesi hidromelioracijskih i hidroregulacijskih radova, izgradnja mreža cesta i željezničkih pruga, osuvremenjivanje poljodjelske proizvodnje i razvoj industrije, te razvoi noviijh nodalno - funkcionalnih gravitacijskih središta). Granica se istina između Austrijskog (dakle i Slovenije) i Mađarskog dijela monarhije nije mijenjala, ali unutar pojedinih djelova Habsburške imperije to dolazi do znatnijeg izražaja. U slučaju Istre to znaći nestanak Pazinske grofovije i ujedinjavanje Istre kao jedne administrativno - teritorijalne cjeline, kojoi su interesno, ali ne i etnički opravdano pridodati i neki kvarnerski otoci. Takav političko geografski razvoj u to doba osnov je i djela međudržavnog graničnog sukoba između R Hrvatske i R Slovenije. (Prinz, 1936)
} 
kojem slučaju niti pravno a niti geografski nije prihvatliiva kao granica. U prošlosti granicu na moru određivala je maksimalna udalienost djelovanja obalnih topovskih baterija, što je dužinu državnih granica bitno ograničavalo. Tehnološkim razvojem ta se udaljenost djelovanja povećavala što je ujedno rezultiralo povećanjem državnog teritorija (†očnije površine teritorijalnog mora), ali je ujedno u najčešćem broju slučajeva skračivalo dužinu granica. Prije 1. Svjetskog rata državne granice na moru povlačene su na 5560 metara od kontinentske obale, no nije se računalo s tehničkim napretkom. Naknadno proširivanje teritorijalnog mora do udaljenosti od 18500 metara (12 morskih milja) također se nije pokazalo dovoljnim. Postavilo se osim toga i pitanje pripadnosti podmorja. U slučaju razgraničenja R Hrvatske i R Slovenije U akvatoriju Piranskog zaljeva svi navedeni kriteriji nisu primjenjivi, pa je riješenje spora vezano za odgovarajući razumni dogovor prihvatljiv za oba suvereniteta.

Za razliku od vodotoka u nizinama u planinskim područjima doline i kotline predstavljaju temeljne osi života političko - teritorijalnih entiteta (države, oblasti, županije...); dolina Save Kranjske, izvorišni dio Drave Koruške, dio doline Drave i Mure Štajerske, Kupa i Sava Zagrebačke te Orljava i Sava Požeško - Slavonske županije u Hrvatskoj itd. U svim navedenim primjerima do izražaja u povlačenju granice je došao geomorfološki princip jedinstva porječja - bazena, pa su međe pojedinih pokrajna i drugostepenih administrativno - teritorijalnih cijelina povučene uglavnom najvišim grebenima uzvišenja, točnije razvodnicama porječja.

\section{Zaključak}

lako prirodna osnova ne može biti odlučujući kriterii pri povlačenju granica historijsko - geografski razvoj istraživanog područija ukazuje da su se u razgraničavanju pojedinih regija $u$ znatnoj mjeri koristile prirodne međe, kojima se prilagođavala prostorna organizacija života. Vrijedi to za veći dio današnje granične linije, koja svoj kontinuitet ima čak od 10. ili pak 12. stoljeća. Preko $75 \%$ granične linije veže se za markantne elemente prirodne osnove, i to prvenstveno za vodene tokove i grebene gorskih uzvišenja ili pak za vršne padine viših gora i planina. Djelovi granice povučene u 20. stoljeću, ma da se također vežu dobrim djelom za prirodne međaše, u cijelosti se mogu karakterizirati kao nametnute, što svog izraza ima u suvremenim graničnim sporovima između R Hrvatske i R Slovenije. 


\section{Literatura i izvori}

Bognar A., Pepeonik Z., 1995; Tipology of Croatia's Borderlands: Politicalgeographical Factors and Implications for Economic-administrative Organization European and regional Development and Planning: Changing Borderlands, The AAG, 91 st Annual Meeting Chicago.

Bognar A., 1997, Beyond Borders: Regional and Local Perspectives, Pannel Discussion on 93 th Congress AAG, Forth Worty, Texas, 1-5, April 1997.

Bognar A., 1987. Geologija i reljef Jugoslavije (s geomorfološkom kartom), Veliki geografski atlas Jugoslavije, Sveučilišna naklada Liber, Zagreb

Bognar A., 1987, Tipovi reljefa Hrvatske, Zbornik II. Znanstvenog skupa geomorfologa SFRJ, Gospić-Južni Velebit 18-25.VI.1987., Geografski odjel PMF-a, Zagreb.

Klemenčić M., 1992, A recent Historico-geographical Basis of the Jugoslav Outer and Inner Bordes with special Reference to Croatian Borders, Geographical papers, vol 8, HGD, Zagreb.

Bufon M., 1994., Theory and Practice in Central European Border Areas: The Slovenian Example, Croatia - New European State, Department for Geography and Spatial Planning, Faculty of Science, University of Zagreb, Zagreb.

Pavić R., 1973, Osnove opće i regionalne političke geografiie, geopolitike i geostrategije, I. dio, Fakultet političkih nauka, Sveučilišta u Zagrebu, Zagreb.

Prescott J.R.W., 1967., The Geography of Frontiers and Boundaries, Hutchinson and CO LTD. London.

Prinz Gy.,1936, Magyar Foldrajz, Az Allamfoldrajzi Kep, III Kotet, Kiralyi Magyar Egyetemi Nyomda Budapest, Budapest.

Pounds JG, 1963., Political Geography, McGraw-Hill Book Company, INC, New York

Martinez O.J. 1994., The Dynamics of Border Interaction, World Boundaries, Edited by Clive H. Schofield

Veliki geografski atlas Jugoslaviie, 1987., Sveučilišna naklada Liber, Zagreb

Topografske karte mierila 1:100.000 po Greenwich-u, Trst, Rovinj, Rijeka, Delnice, Kočevje, Postojna, Ogulin, Karlovac, Novo Mesto, Zagreb, Ptuj, Varaždin, Murska Sobota, Vojnogeografski Institut, Beograd. 


\title{
INFLUENCE OF THE NATURAL-GEOGRAPHIC BASIS ON DEVELOPMENT OF THE CROATIAN-SLOVENE BOUNDARY LINE
}

\begin{abstract}
Summary
The major part of the boundary line between the Republic of Croatia and Slovenia has charactristics of a subsequent boundary, defined by the centuriesold political-economic and ethnically appropriate accommodation of the life organization. In accordance with that there is a borderland accommodated to the natural geographic features of the area. The boundary line along the rivers (Kupa, Čabranka, Bregana and the source part of the river Sutla) and mountain ridges (Maceliska gora, Žumberačka gora and the mountainous area of the High Karst: Veliki Snežnik and Croatian Snježnik, Obruč, Petelinek and the mountainous group Čičarija). However, the more recent boundary, fixed after the First and the Second World War, has characteristics of an imposed or superimposed boundary reflecting the momentary relations of the forces and interests of particular sovereignties. In accordance with specific geomorphological,especially hydromorphological characteristics of the area, and with the historical development (cadastral system, gravitational relations and ethnic arrangement), those parts of the boundary line are burdened with a series of illogicalities representing today the basis for the borderland disputes between the two sovereignties. This especially concerns the question of the sea boundary line and of that on the river Dragonja, and also partly the question of the boundry line on the river Mura.
\end{abstract}

